\title{
Piql. Long-term preservation technology study
}

\author{
Jędrzej Sabliński \\ Piql Polska / Piql Poland \\ sablinski@di-factory.com \\ Alfredo Trujillo \\ Piql AS (Norway) / Piql AS (Norwegia) \\ alfredo.trujillo@piql.com
}

\begin{abstract}
The purpose of the analysis is to demonstrate the effectiveness of Piql technology data storage for long-term preservation. This technology has been confirmed by certified laboratory tests. The article presents a unique and effective technology for perpetual storage of data on physical media and a detailed description of data recording methods, including the equipment needed for this process. It also presents the conditions of packaging, storage, transport and protection of piqlFilm media, based on the experience of durability of this medium over the past several decades. The idea behind the creation of this technology, in addition to permanent storage, is the ability to read the stored data in the distant future. The data is stored in an open format, allowing read access without temporal or technological limitations. Piql has also, taking advantage of the unique geo-climatic conditions on the Arctic island of Svalbard, established a specialized archive called the Arctic World Archive or the End of the World Library, to store the most valuable data of international institutions and companies as well as the world's cultural heritage.
\end{abstract}

\section{Piql. Studium technologii długotrwałej ochrony STRESZCZENIE}

Celem analizy jest przedstawienie skuteczności zapisu danych w technologii Piql, w celu ich długoterminowej ochrony. Technologia ta została potwierdzona certyfikowanymi badaniami laboratoryjnymi. W artykule została zaprezentowana unikalna i skuteczna technologia wieczystego przechowywania danych na nośniku fizycznym oraz szczegółowy opis metod zapisu danych, wraz z urządzeniami potrzebnymi do tego procesu. Przedstawiono także warunki pakowania, magazynowania, transportu i zabezpieczenia nośnika piqIFilm, bazując na doświadczeniach trwałości tego nośnika z ostatnich kilkudziesięciu lat. Ideą przyświecającą stworzeniu tej technologii, oprócz trwałego przechowania, jest możliwość odczytu zapisanych danych w odległej przyszłości. Dane są przechowywane w formacie otwartym, umożliwiającym dostęp do odczytu bez ograniczeń czasowych i technologicznych. Piql stworzył również specjalistyczne archiwum, wykorzystujące unikalne warunki geo-klimatyczne na arktycznej wyspie

\section{KEYWORDS}

preservation, long-term data storage, digitization, archiving, Arctic World Archive, End of the World Library

\section{SŁOWA KLUCZOWE}

ochrona, długoterminowe przechowanie danych, digitalizacja, archiwizacja, Światowe Archiwum Arktyczne, Biblioteka Końca Świata 
Svalbard, nazwane Światowym Archiwum Arktycznym (Arctic World Archive) lub Biblioteką Końca Świata (End of the World Library), w celu przechowania najcenniejszych danych międzynarodowych instytucji i firm oraz światowego dziedzictwa kulturowego.

\section{Introduction}

Piql is a Norwegian technological company specializing in long-term archiving of digital data. Piql also consults and develops digitization and archival strategies. Piql Polska has been operating in Poland since February 2020.

Piql has created a holistic data preservation solution ${ }^{1}$ where data integrity and authenticity is preserved using a solid medium with a well-documented lifetime. The solution includes features that will allow users in the future to recreate the reading technology using the information written on the medium.

The technology is based on storing digital data on a photosensitive polyester film, creating a secure, migration-free, long-term preservation solution for data. This digital preservation medium is designed to last over 1000 years and to ensure that future generations would be able to access the information. Piql combines the longevity of polymers and silver halides with the ability to store the instructions on how to decode the data stored on the film in a human-readable format.

This article describes the data preservation technology, steps taken to ensure authenticity of the data, and the processes involved in preserving and retrieving data from the film.

\section{Technology Overview}

Piql's technology uses an optical recording medium for digital storage - a 35mm width polyester film coated with a gelatin emulsion containing microscopically small light-sensitive silver halide crystals. The silver halides darken when exposed to light. Piql used this characteristic to expose binary data in frames along the film. The film is exceptionally stable and tested to last for centuries.

The software technology used to decode the data is open-source, freely available and was tested using several operating systems. The hardware technology

1 B.H. Brudeli, K.-M. Drake, A Holistic Approach to Digital Preservation, Piql preservation solution - outcome from Norwegian and European research projects (Archivator, MiLos, AsToR). Piql AS Paper. 
to capture data from the film is widely available, and the only requirement is an image capturing device capable of sampling images as a 2D array of colour intensity values.

There are three main hardware components used to store digital data on film. First, the piqlWriter, a device using photons to transfer data onto the film medium. In the next stage, the photochemical processor (piqlProcessor), a machine where the information written on the film is chemically developed and fixed to ensure image presence and permanence. Finally, the piqlReader, a device reading frames from the film and converting them into sampled images which are decoded back to digital data ${ }^{2}$.

The piqlWriter and piqlReader were built as dedicated devices for the Piql technology. The piqlWriter is used mostly for the preservation process, providing integrity and authenticity to the data. To retrieve the data from the film, the only component needed is the piqlReader.

\subsection{Piql Writer}

The piqlWriter receives the encoded binary data as a set of files representing the recordable images (frames) and writes them on the film at a high speed. The speed of the piqlWriter is $20 \mathrm{fps}$ (frames per second) $\sim 2 \mathrm{M} \mathrm{B}$ per frame $=40 \mathrm{M} \mathrm{B} / \mathrm{s}$.

\subsubsection{W riting Technology}

There are several technology elements in the piqlWriter. The core technology element that ensures data reliability on film is the imaging technology. Imaging is based on a Texas Instruments ${ }^{3}$ Digital Lightning Processing (DLP) imaging sensor with $4 \mathrm{~K}$ resolution (4096 x 2160 pixels), consisting of more than 8'800,000 micro-mirrors capable of writing pixels of $6 \mu \mathrm{m}$ size. The piqlWriter uses a monochromatic green LED light which is modulated by the DLP. The DLP micro-mirrors tilt either toward the light source $(\mathrm{ON})$ or away from it (OFF) creating a light or dark pixel on the projected film surface.

2 piql AS, Piql Technology - behind the scenes, https://www.piql.com/whitepapers/other-paper/ piql-technology-behind-the-scenes. Accessed 29.11. 2021.

3 Texas Instruments Inc. (abbr.: TI) is an American technology company that designs and manufactures semiconductors. In 1987, TI invented the digital light processing device (also known as the DLP chip). At the time of writing the film the website is: Texas Instruments, http://www.ti.com. Accessed 29.11.2021. 


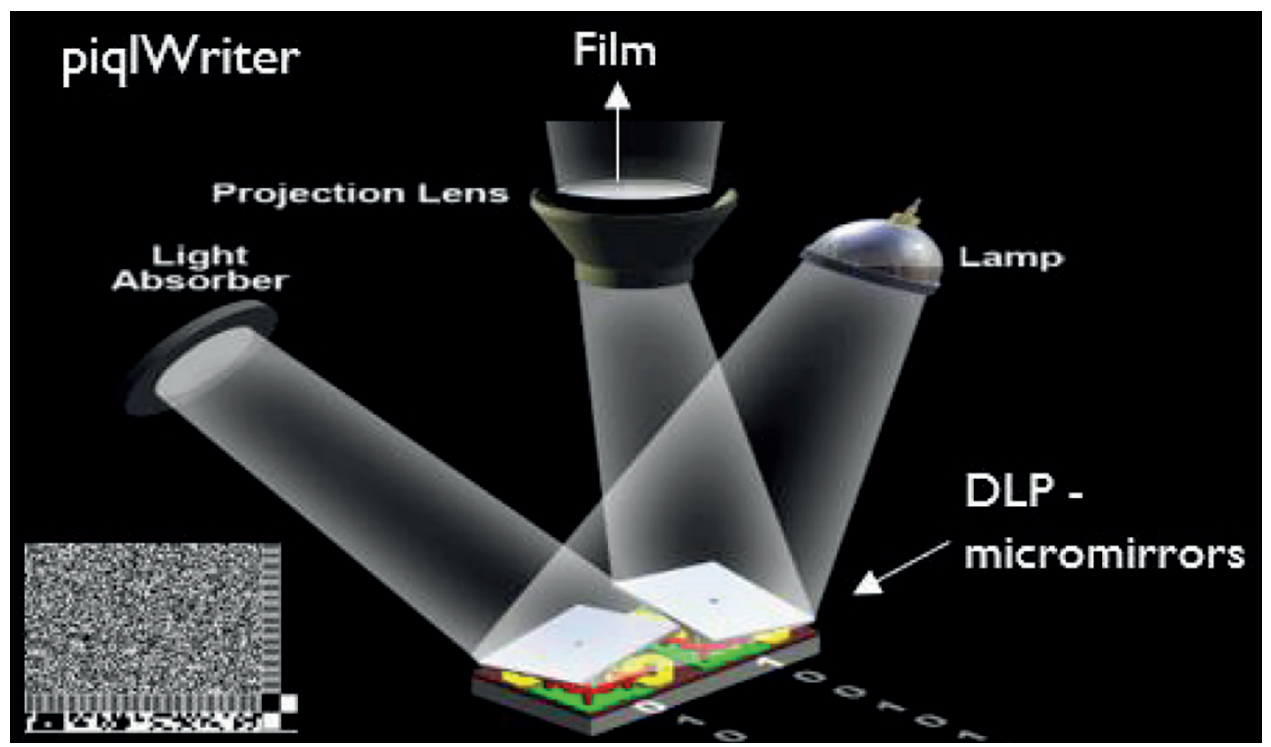

Figure 1. DLP micro-mirrors exposing the film

For Piql's digital application, every pixel represents a binary data container. This exposing technology allows writing pixels with excellent contrast, thus achieving high data density per frame. In this way, it is possible to reproduce the binary stream of the client's digital content.

After exposing the film, the pixels' values cannot be changed, providing a true WORM (Write Once Read Many) storage medium. The Imaging technology, combined with the software and the production processes makes the data content in this film secure, integral and reliable.

\subsubsection{Data preparation}

When a set of files have been selected for preservation, they are uploaded to the Piql system. This will automatically start a data preparation process. This process serves two main purposes; to collect and store relevant metadata to enable future access to the data and to encode the data and file metadata into the Piql system storage format, which is 2D barcode image.

There are three types of metadata used during the data preparation process:

1. Metadata for the reel and the frames, called administrative and technical or structural metadata. This information is used by the system to decode each individual frame. (Bit depth, frame number, Forward error correction algorithm, etc.). 
2. Metadata named "Representation information" in the OAIS ${ }^{4}$ (Open Archival Information System) reference model for digital repositories, which represents all the information needed to decode and reproduce the files in the future. This metadata contains the decoding open source code, software description, descriptive documents of Piql technology and file format specifications.

3. File descriptive metadata named "Preservation Description Information" (PDI) in the OAIS reference model. This is all the metadata the user wants to associate to the file to give it better context (file name, creator, provenance, property rights, etc.).

Data preparation comprises following steps:

1. Metadata is collected from the set of files; administrative and technical metadata used by Piql system is added.

2. The files are split into smaller elements, each containing the amount of data that can be stored within one recorded image, also referred to as a data frame.

3. Forward error correction is applied to the elements to ensure that the data can be correctly restored in the future. In addition, interleaving is applied to avoid bursts of errors.

4. The data frames are created, including pixel tracking information and metadata.

\subsubsection{Reel Format ${ }^{5}$}

Each reel will include all data needed to retrieve the content in the future. Several measures are taken to ensure this. The reel is divided into following sections, as shown in Figure 3:

A. Before the actual reel format starts, 16 patch grey scale frames are written for film quality assurance.

B. Every reel starts with a zero-reference mark, making it possible to accurately and automatically position the piqlReader at the beginning of a reel. The location of every frame on the reel is linked to the zero-reference mark, making it possible to wind to a specific part of the reel at high speed, thus reducing the access time.

4 Recommendation for Space Data System Practices. Reference model for an Open Archival Information System (OASIS). Recommended practice CCSDS. 650.0-m-2 Magenta Book. June 2012, http://public.ccsds.org/publications/archive/650x0m2.pdf. Accessed 29.11.2021.

5 Generic Preservation Reel Structure Specification, Piql AS, rev. 170125. 
C. Following the zero-reference mark is a control section containing a set of administrative and technical metadata. The control section is recorded using both digital and analogue representation, meaning that the metadata is also human-readable with simple means such as a light source and a loop. The administrative metadata contains information that can be used for identifying the reel, date of recording, and the data owner information. The technical metadata is data needed to decode the data frames. This metadata includes the physical layout of the frame, the forward error correction and interleaving algorithms used, the number of bits stored in every single pixel, and frame numbers of the Table of Contents (TOC) section.

D. The TOC section is a table of contents for the entire reel. It includes information like where on the reel specific files are located, size of individual files and checksums for each stored file.

E. Representation Information including documents in human-readable format describing how to recreate the content in case the technology is not available in the future.

F. The content area contains the data frames and file metadata frames. These are printed in digital, visual, or both formats (hybrid).

G. The control section and TOC section are repeated at the end of the reel for redundancy.

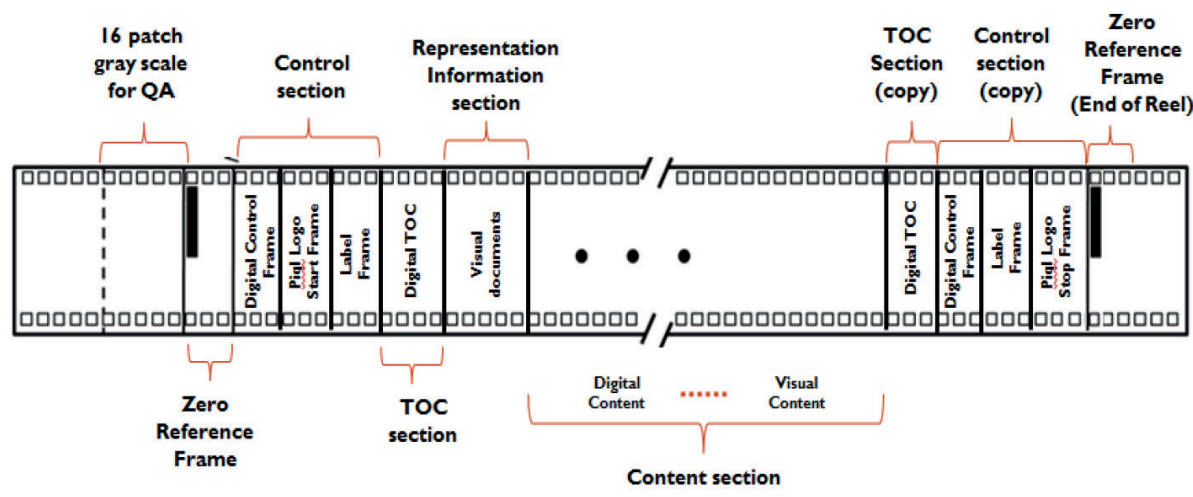

Figure 2. Reel Layout

In short, the zero-reference frame is used to position the reel in the piqlReader. The control section is used to get all information needed to decode the rest of the frames. The TOC section is used to locate specific files on the reel. All are combined for reading and retrieving the files from the film. 


\subsubsection{Frame Format ${ }^{6}$}

Each data frame consists of several parts, as shown in figure 4 . The size and format of each element are precisely defined in the control section described above to make it easy to decode the frame.

The structural metadata bar contains information about the current frame. This includes type of frame (Control, TOC, visual frame or digital frame), the checksum for the content, identifier for the reel, identifier for the file the frame belongs to, and other similar information.

Corner marks and reference bars are used for automatic pixel tracking. The human-readable bar is used for the frame number. The calibration bar is a grey level pattern representing the pixel's binary values used for sampling the data.

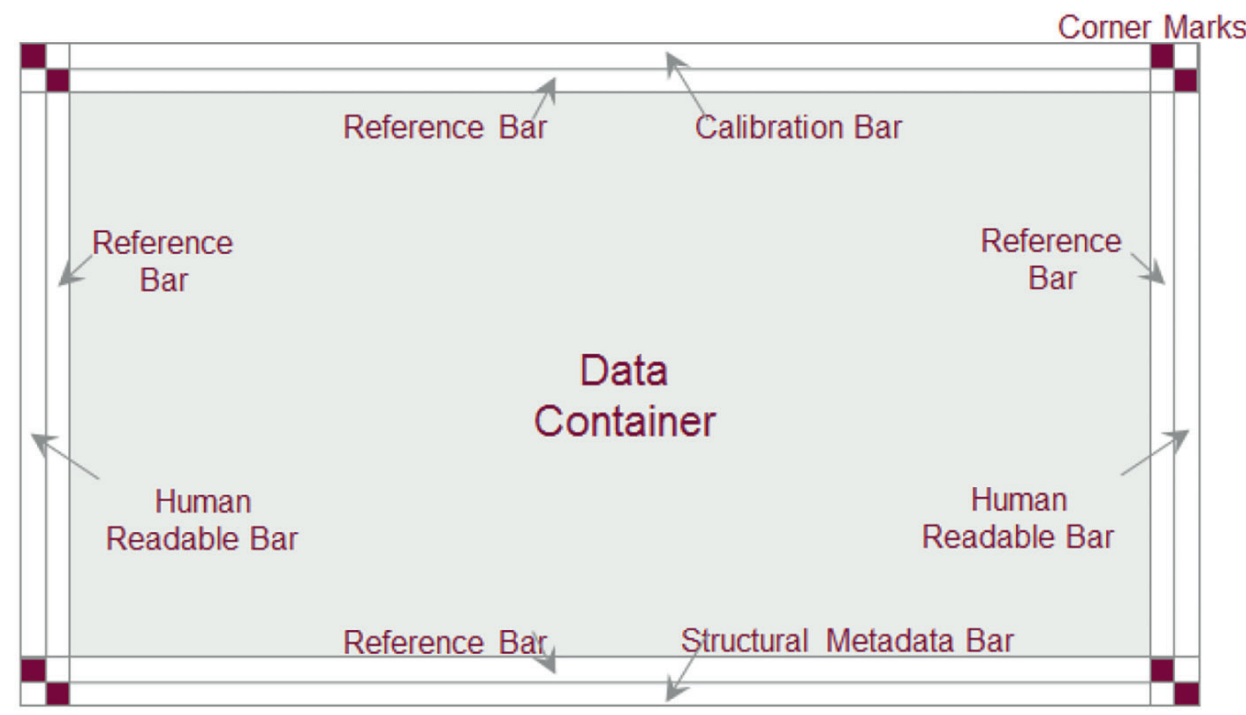

Figure 3. Frame Layout

\subsection{Piql Processor}

In the piqlProcessor, which is a photochemical processor, the information written on the film is chemically fixed. The latent silver halide particles exposed to light are converted into metallic silver and fixed to ensure data permanence on

6 Generic 4K Frame Format. 4K Frame Structure description, Piql AS, rev. 170630. 
the film. Processing is an essential step in the workflow behind data preservation. Piql has built a dedicated processor for the photochemical processing, but commercially available processors can also be used.

Piql uses two different chemical processes for developing the piqlFilm. The first, and most used, is Kodak D97 and the second is MFD (MicroFilm Developer).

Table 1. below describes the processing steps of black and white film.

Table 1. Black and White film processing steps.

\begin{tabular}{l|l}
\hline \multicolumn{1}{c|}{ Step } & \multicolumn{1}{c}{ What Happens } \\
\hline Developer & $\begin{array}{l}\text { Develops the exposed latent-image silver halide to metallic silver - } \\
\text { particularly important for obtaining desired contrast and density. }\end{array}$ \\
\hline Wash & Removes developer from film. \\
\hline Fixer & Removes unexposed and underdeveloped silver halide from the film. \\
\hline Wash & Removes fixer from the film. \\
\hline Dryer & Dries the processed film in preparation for data verification. \\
\hline
\end{tabular}

A developer is characterized by its formula and processing settings. Table 2 provides an overview of different processing times for $\mathrm{D} 97$ process. The standard temperature for each step is $21^{\circ} \mathrm{C}\left(70^{\circ} \mathrm{F}\right)$.

Table 2. Overview of different processing times for D97.

\begin{tabular}{l|c}
\hline \multicolumn{1}{c|}{ Processing Steps } & Time, minutes at $\left.\mathbf{2 1}^{\circ} \mathbf{C} \mathbf{( 7 0}{ }^{\circ} \mathbf{F}\right)$ \\
\hline D97 developer & 6 (for piqlFilm) \\
\hline Wash (water) & 3 \\
\hline Fixer & 9 \\
\hline Wash (water) & 10 \\
\hline
\end{tabular}

The chemicals used in D97 developer are described in Kodak documentation (See Table 3. below, reference to Kodak website - support documentation: "Processing KODAK Motion Picture Films, Module 15P rocessing Black-andWhite Films"7).

Table 3. presents an overview of how many liters of developer and fixer solutions should be made. The main baths, named working tanks, hold 370 liters,

7 Processing KODAK Motion Picture Films, Module 15. Processing Black-and-White Films, 2000, https://www.kodak.com/content/products-brochures/Film/Processing-KODAK-MotionPicture-Films-Module-15.pdf. Accessed 29.11.2021. 
and external replenisher tanks hold 100 liters. The order of chemicals used in the mixing process is reflected in the table (starting at the top). Every ingredient must be completely dissolved before the next one is added.

Table 3. Overview of chemicals used for developer (DEV) and fixer (FIX) solutions. WRK stands for working tank and REPL stands for replenisher.

\begin{tabular}{l|l|c|c|c|c}
\hline \multicolumn{1}{c|}{ Solution } & \multicolumn{1}{|c|}{$\begin{array}{c}\text { Formula or } \\
\text { Chemical name }\end{array}$} & $\begin{array}{c}\text { DEV } \\
\text { WRK }\end{array}$ & $\begin{array}{c}\text { DEV } \\
\text { REPL }\end{array}$ & $\begin{array}{c}\text { FIX } \\
\text { WRK }\end{array}$ & $\begin{array}{c}\text { FIX } \\
\text { REPL }\end{array}$ \\
\hline Required volume, L & & 370 & 100 & 370 & 100 \\
\hline Water start volume, L & & 278 & 75 & 278 & 75 \\
\hline Dequest 2006, kg & C3H7NNa5O9P3 & 0,37 & 0,1 & 0,37 & 0,075 \\
\hline Elon/Genol, kg & $\begin{array}{l}\text { 4-(Methylamino) } \\
\text { phenol Sulfate }\end{array}$ & 0,185 & 0,07 & & \\
\hline Sodium Sulfite, $\mathrm{kg}$ & Na2SO3 & 14,8 & 7 & 5,92 & 1,6 \\
\hline Hydroquinone, $\mathrm{kg}$ & Paradihydroxybenzene & 1,11 & 1,1 & & \\
\hline Sodium Carbonate, $\mathrm{kg}$ & $\mathrm{Na2CO3}$ & 7,4 & 2 & & \\
\hline Sodium Bromide, $\mathrm{kg}$ & $\mathrm{NaBr}$ & 0,648 & 0,13 & & \\
\hline Sodium Hydroxide, $\mathrm{kg}$ & $\mathrm{NaOH}$ & & 0,2 & & \\
\hline Ammonium Thiosulfate, $\mathrm{kg}$ & $(\mathrm{NH} 4) 2 S 2 \mathrm{O} 3$ & & & 21,2 & 5,7 \\
\hline Sodium Metabisulfite, $\mathrm{kg}$ & $\mathrm{Na2S2O5}$ & & & & 0,58 \\
\hline Water end volume, L & & 92 & 25 & 92 & 75 \\
\hline
\end{tabular}

When mixing the developer and fixer solutions, two external tanks should be used, one for each solution. After the mixing process is completed, quality controls of developer solutions $\mathrm{pH}$ values are to be conducted. $\mathrm{pH}$ of the developer WRK should be between 10.12 - 10.22, and pH of the developer REPL should be 10.23 - 10.31. After that, the solutions are transferred to their respective tanks in the processor machine using a pump.

\subsubsection{Processor throughput}

The Piql process starts with exposing digital data on a film reel using the piqlWriter, developing the film reel in the processor and finally verifying the film reel using the piqlReader (session 2.3). The length of a full reel of piqlfilm is $950 \mathrm{~m}$. The processor speed determines the throughput rate of the film.

The piqlProcessor operation time for one piqlFilm at $30 \mathrm{~m} / \mathrm{min}$ is: 


\subsubsection{Silver recovery}

Piql uses a Silver Recovery Unit to extract silver from the fixer bath after the development process is completed. This process protects the environment by recycling the silver before wastewater is discharged.

An electrolytic silver recovery system is used; it recovers approximately $95 \%$ of silver present in the fixer bath. The silver recovered by electrolytic methods is generally 98-99\% pure.

Estimated silver Recovery from a reel of piqlFilm (950 meters) is $2.0 \mathrm{~kg}$ of silver recovered from fixer per 24 hours.

\section{3. piqIReader}

The piqlReader is a high speed, high-resolution digital data scanner. It captures images from the film and restores digital and visual data.

The piqlReader is used for two preservation steps. The first step is data verification after the film has been chemically processed. This step ensures that data written on film is authentic and readable.

The second step is data retrieval from the film. When a user requires data from the film, the piqlReader is used for accessing the data. The piqlReader can be acquired by a user, or Piql can provide data retrieval services on demand.

The piqlReader features precision mechanical film handling components, customized optics, a diffused $405 \mathrm{~nm}$ LED light source, a built-in fast line rate $12 \mathrm{~K}$ camera (optics) and a high-performance computer. It runs open-source software for capturing images and decoding them to digital data in real-time.

Retrieving digital data from film requires two processes running in parallel. The first process is capturing the image from the film, and the second is decoding that captured image file.

- The piqlReader reads in continuous mode at 12 frames per second. It scans a frame into RAM and decodes the data at the same time as follows.

- The piqlReader searches for the zero-reference mark to set the starting reading reference.

- It decodes the control frame (first frame) and provides all parameters for decoding the following frames.

8 PiqlReader. Technical specifications, Piql AS, rev. 200205. 
- It reads the Table of Contents, identifies the frames corresponding to the file requested, and forwards the film to the location of those specific frames.

- The content frames are scanned, decoded, and the file is restored. The file is verified through calculating its checksum and comparing it to the checksum written in the Table of Contents of the film. After a successful verification, the file is made available to the client for download.

The software technology used to decode the data is open-source, freely available and was tested using several operating systems. The code is written on the piqlFilm in readable format for future reproduction. Besides, the decoding software is publicly available in the GitHub public site. The software consists of two parts ${ }^{9}$, the software decoding individual image frames (https://github.com/ piql/boxing) and the software assembling all decoded frames and building the files (https://github.com/piql/afs). Installation and operating instructions are described in each repository. The piqlReader user interface allows the operator to run the decoding applications.

The piqlReader includes a $35 \mathrm{~mm}$ film gate, a capstan drive for continuous movement of the film, film spools, protection against unwinding, integrated user interface, and desk mount form factor. All these components allow simple operation, minimum wear of the film and easy maintenance. The piqlReader can be operated as a winding table for forwarding and rewinding of film.

The piqlReader data retrieval speed is $24 \mathrm{MB} / \mathrm{s}$ (12 frames per second). A whole piqlFilm reel is decoded in 1.5 hours. Winding speed is $3000 \mathrm{~mm} / \mathrm{s}$ (200 frames per second). The vertical form factor allows installing the piqlReader in an office environment. The dimensions are 106 x 53 x $99 \mathrm{~cm}$ ( w x d x h) and weight $180 \mathrm{~kg}$.

\section{The Storage Medium}

The piqlFilm (the storage medium) is a polyester film base coated with a gelatin layer of light-sensitive silver halides. The storage medium's physical properties are the same as $35 \mathrm{~mm}$ photographic and motion picture films. It follows all SMPTE ${ }^{10}$ (Society of Motion Picture and Television Engineers) motion picture standards.

9 GitHub, Boxing, https://github.com/piql/boxing. Access 26.10.2021; GitHub, Archival File System, https://github.com/piql/afs. Access 26.10.2021.

10 “SMPTE Motion Imaging Journal", 2003-09, vol. 112, No 9, DOI 10.5594/SMPTE.ST139.2003, https://archive.org/details/sim_smpte-motion-imaging-journal_2003-12_112_12. Accessed 26.10.2021. 
Following these standards ensures that the film can be chemically processed and verified using commercially available equipment, such as processors.

The film is exposed with light to store a latent image with digital data. The film is then processed using a series of chemical baths, making the latent image permanent. The image permanence aspect makes the film a true WORM (Write Once Read Many) digital storage medium, meaning that digital information can be safely stored and remains unchanged. The film cannot be hacked, the data cannot be manipulated, a virus cannot infect it, and it cannot be affected by electromagnetic pulses and that makes it an ideal digital storage medium.

The piqlFilm ${ }^{11}$ is a low-speed, high-contrast, black and white, negative film with an extremely fine grain (20 nm to $40 \mathrm{~nm}$ ) and high resolving power (1180 line pairs per $\mathrm{mm}$ ). The film has been optimised for the piqlWriter's exposing system to $520 \mathrm{~nm}$ wavelength.Moreover, the film has been optimised for stress, friction, and conductivity, so that it would move easily through the piqlReader.

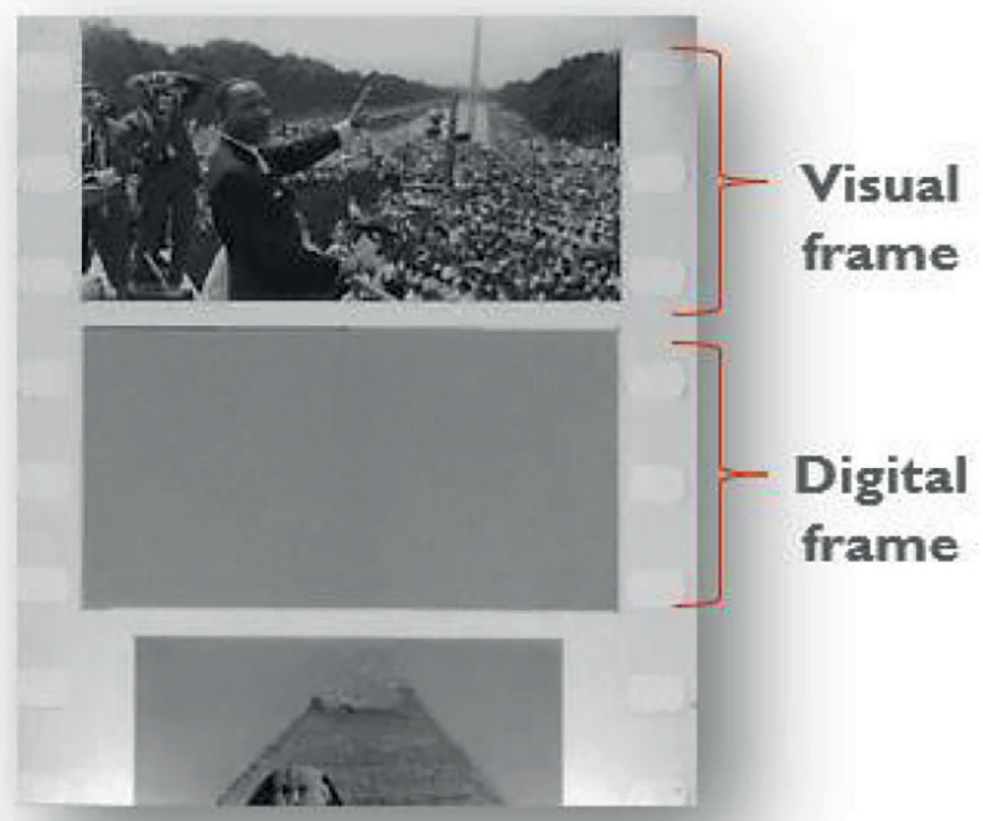

Figure 4. Visual and Digital Frames

11 piqlFilm product specification, Piql AS, rev. 180121. 
The film went through extensive longevity testing under ISO standards ${ }^{12}$, which demonstrated its resilience and capability to decode data after more than 1000 years $^{13}$.

When comparing the film to traditional storage mediums such as magnetic tape, both mediums can write binary information (film using light and magnetic tapes using iron particles), but the film is self-contained. "Self-contained" means that the film includes information in a human-readable format which allows recreate the reading technology, as well as the information to ensure understandability and readability of the digital data in the future. Other traditional mediums rely on external hardware and software technology to decode and read the files; it is not possible to recreate the reading technology using only the medium itself.

\subsection{The piqlBox}

A customized storage container, the piqlBox, was manufactured from polyester material and tested to ensure the same longevity properties as the film. The piqlBox and the piqlFilm were tested together to make sure the piqlBox's material did not have any negative impact on the film. The piqlBox was designed to protect the film and to avoid excessive manipulation of the film during the preservation workflow.

\section{Preservation Workflow}

\subsection{Data ingestion}

Data ingestion processing starts from the moment the user uploads a file and ends when the information is stored on film. Before writing the data on film, there is an essential process of preparing the data for sustainability.

12 ISO18901:2010 Imaging materials - Processed silver-gelatin-type black-and-white films Specifications for stability; ISO 18936:2012 Imaging materials - Processed colour photographs Methods for measuring thermal stability; ISO 18924:2013 Imaging materials - Test method for Arrhenius-type predictions.

13 Test Rapport (TR) for Longevity of the Photographic film P1 from Kodak, Norner Project No 2222160, Technical Report 26.10.2021. 
Sustainability is the process of analyzing the files and the metadata, verifying their authenticity, and normalizing them to open source, non-proprietary file formats that are self-described and well documented. At the end of this process, the files are contained in an Archival Information Package (AIP) defined by the OAIS reference model.

Only quality controlled and verified AIPs are accepted for writing on film. The AIP includes digital data objects (e.g. text files; images; video; sound; data animation; pdf, etc.) and required metadata.

After the AIP is accepted, it is sent to preservation where the AIP is encoded in a set of files representing the recordable images (frames). Then, the frames representing the encoded AIP are written onto the piqlFilm.

\subsection{Data Security}

Data security is ensured during the entire preservation process, from ingestion to physical storage. Most users upload data through piqlConnect, a web application for managing and accessing the user files. piqlConnect supports single Sign-In, OAuth2 and OpenID protocols for access authentication. During the transfer, the data is encrypted using HTTPS.

HTTPS is used when transferring the encoded data to the Piql System. The Piql system is configured to work in a closed network environment. The receiving data server is protected by firewalls with restricted access ports.

\subsection{Data Integrity}

The Piql system is designed to prevent unintentional changes to the information and ensure all data is written and retrieved with the highest possible data integrity. Before writing the data, Forward Error Correction (FEC) techniques and checksums are used to make sure the accuracy and authenticity of the data are maintained throughout the entire preservation process.

The solution implements data redundancy applying standard FEC algorithms (Cross-Interleaved Reed-Solomon Coding $\left.(\mathrm{CIRC})^{14}\right)$ used by traditional storage mediums like CD, DVD, Raid disk, etc. The FEC algorithm used provides

14 Cross-Interleaved Reed- Solomon Coding (CIRC), Wikipedia The Free Encyclopedia, https:// en.wikipedia.org/wiki/Cross-interleaved_Reed\%E2\%80\%93Solomon_coding. Accessed 29.11.2021. 
redundancy within a frame, so if a frame is scratched or has areas with mechanical damage, the information can still be recovered. The data is also distributed along several frames (data splitting), so it is possible to lose entire frames and still be able to decode the data.

The second element to provide integrity is the checksum. A checksum or hash sum is a small-size datum computed from an arbitrary block of digital data for detecting errors that may have occurred during its transmission or storage. SHA1 and CRC64 checksums are used to ensure data integrity. SHA-1 (Secure Hash Algorithm 1) checksum was initially developed as a cryptographic hash function, but it is widely used for ensuring that the data has not changed due to accidental corruption. In SHA-1, given 10.000.000.000 single files, the chance of collision is $\sim 3,4 \times 10-29$.

The client is asked to calculate the SHA-1 checksums of their files before transferring to Piql. After the files are received, the checksum (SHA-1) is generated for the files, verified against the client's calculated checksums, and saved in the system database for a final integrity check.

The files are decoded and split into small elements of information (binary form) that fit into a frame. For each frame to be written, another checksum (Cyclic Redundancy Check - CRC64) is generated and added to the data frame before sending it to the piqlWriter.

CRC64 checksums are well suited for detection of burst errors during transfer, and the probability of one block colliding is $\sim 1,8 \times 10-19$.

The piqlWriter's firmware has a built-in checksum generator, so when the piqlWriter receives a frame, it calculates the CRC64 checksum and compares it with the CRC64 checksum it received. This way, each frame's checksum is verified, assuring data integrity during transmission, and then written on film.

\subsection{Data Verification}

Data verification is the final quality assurance process before physical storage and assures that the information stored on film is readable.

Data verification is performed using the piqlReader. The entire reel is scanned, and each frame is analysed and decoded. The application rebuilds the digital files, calculates the SHA- 1 checksums, and compares them with the ones stored in the database. After successful verification, the client's original files are deleted, and 
the reel is ready for physical storage. (See section 2.3 piqlReader for operation details).

\section{Transportation and Storage Instructions ${ }^{15}$}

Photographic films are susceptible to degradation from many sources. The conditions under which the piqlFilm are stored are extremely important for the preservation of the film and thereby preservation of the data.

The important parameters affecting preservation of processed film are humidity, temperature and air pollutants as well as the hazards of fire, water, light, fungal growth, insects, microbiological attack, and physical damage.

\subsection{Transportation}

The piqlFilm should be transported in as stable temperature as possible. Temperatures above $30^{\circ} \mathrm{C}$ should be avoided in particular.

\subsection{Handling}

Gelatin film becomes more brittle at low temperatures (below $0{ }^{\circ} \mathrm{C}$ ). To avoid undue flexing, films should be handled carefully when in low-temperature storage. Flexibility is restored upon return to room temperature.

Films stored at temperatures significantly below room temperature will require 24 hours warm-up time before they can be used.

For bagged films, allow the film to come to room temperature (24 hours) before opening, to avoid condensation. Rebag and seal the film before returning it to storage. Time out of storage should be minimized to maintain life expectancy of the film.

\subsection{Long Term Storage Conditions}

Temperature: maximum $21^{\circ} \mathrm{C}$ (cycling of temperature should not be greater than $\pm 2{ }^{\circ} \mathrm{C}$ over any 24-hour period).

15 piqlFilm - Transportation \& Storage Instructions based on ISO 18911:2010(E) and ANSI ${ }^{\circledR}$ IT9.11-1991, Piql AS, rev.190902. 
Relative Humidity: 20-30\% (Cycling of relative humidity should not be greater than $\pm 5 \%$ RH over any 24-hour period and should not be less than the lower $\mathrm{RH}$ limit or greater than the upper $\mathrm{RH}$ limit).

Orientation: the piqlFilm shall be stored horizontally in the piqlBox.

Foil Bag: Heat-sealed foil bags should be used when the storage temperature is below $10^{\circ} \mathrm{C}$. Limit, as much as possible, the volume of free air in the sealed film container.

\section{Arctic World Archive}

The Arctic World Archive (AWA), located on the remote island of Svalbard, Norway, is a repository for world memory. Set 300 metres inside an arctic mountain in a disaster proof vault in the most geopolitically stable place in the world, the data stored here will last for centuries. An initiative of Piql AS, AWA was developed to ensure that our digital memory would be available for future generations, in a world where few places are safe from natural and man-made disasters. Norway, Brazil and Mexico were the first nations to deposit some of their most important data in 2017; since then more and more nations and organisations are choosing to store their most precious data in the Archive. The Archive now holds data from 16 countries. This includes precious manuscripts from the Vatican Library, open source code from Github, UN convention on the rights of the child from UNICEF, Edvard Munch's The Scream, archives from nations around the world, speeches of Albert Einstein, contemporary artworks, photographs capturing historic moments and many other memories. This year we enriched AWA's collection with works of two Polish Nobel laureates - Olga Tokarczuk and Wisława Szymborska.

\subsection{Sustainability}

Data centres around the world are among the biggest consumers of electricity: U.S. data centres use more than 90 billion kilowatt-hours of electricity a year, requiring roughly 34 giant (500-megawatt) coal-powered plants. Last year, global data centres used roughly 416 terawatts (4.16 x 1014 watts) (or about 3\% of the total electricity), nearly $40 \%$ more than the entire United Kingdom.

The Arctic World Archive requires no electricity and therefore has no carbon emissions. The Arctic World Archive is considered one of the greenest data storage 
vaults in the world and has been nominated for sustainability awards. Likewise, Piql's technology is considered a very green solution as it can store data for such a long time without needing electricity or maintenance. Piql was recently awarded the Grønn Gründer (i.e. the "green entrepreneur of the year") for sustainable innovation by Drammen Rotary. Life cycle analysis has shown that piqlFilm was more environmentally friendly than hard drives after just 1.5 years.

\subsubsection{Contribution to UN Sustainability Goals}

Goal 9: Build robust infrastructure, promote innovation and contribute to inclusive and sustainable industrialisation:

Piql helps establish a robust infrastructure for ultra-secure, long-term data storage to the benefit of all nations, organisations, companies and individuals. Piql clearly contributes to innovation in our field. New knowledge in faster lifetime testing provides opportunities for shorter test periods when documenting the lifetime of new innovative sustainable products, which in turn can bring sustainable products to market faster.

Goal 12: Ensure sustainable consumption and production:

A long-life storage medium produces less hazardous waste than a storage medium that must be disposed of after a relatively short time. Hard drives contain electronics and must therefore be treated as special waste, and with migration every 3-5 years there is a lot of waste!

Goal 13: Act immediately to stop climate change and fight the consequences:

piqlFilm is a permanent storage medium that does not consume energy in the same way as a storage medium that requires power (hard drives, magnetic tapes, etc) does to keep the data alive. From a 1000 year perspective, this means huge energy savings. Data centres are now major consumers of electricity, and studies show that transport and storage of digital data account for up to $10 \%$ of the world's total electricity consumption. Life Cycle Analysis (LCA) conducted by Chulalongkorn University in Bangkok compared the storage of 1 TB of data on piqlFilm against 1 TB of data on hard disk for 500 years. The study found that the Global Warming Potential (GWP) of Hard Drives is 38 times higher than that of piqlFilm. In practice, this means that Piql's migration-free storage is "greener" than hard drive storage after only 1.5 years.

Goal 16: Promote peaceful and inclusive societies with well-functioning legal systems and responsible institutions at all levels: 
Data on piqlFilm cannot be altered or overwritten, therefore ensuring that data cannot be manipulated, altered or deleted, as it can be in case of electronic data storage (hard disk) and magnetic tape. This helps to ensure the legal protection of organisations and individuals and to prevent corruption and crime (such as fraud).

Piql continues to pursue greener solutions and has concrete plans to make Piql technology even more environmentally friendly and sustainable.

\subsection{AWA and Climate Change}

There have been reports of Svalbard getting warmer and the ice melting. Fortunately, while piqlFilm is best stored in dry and cold conditions, minor changes in temperature have very little effect on the film. piqlFilm has been tested at very high temperatures that cannot be found on Earth in normal conditions, to extremely low temperatures of -196 degrees (Liquid Nitrogen), to radiation exposure and successful mechanical operation and readback were confirmed. Longevity testing was also carried out to simulate storage over long periods of time. Based on the temperature of AWA, piqlFilm has proven it can last 1000 years. Svalbard wasn't just chosen for its climate; it is also one of the most geopolitically stable places on Earth. AWA is situated 300 metres inside the Mine 3 mountain at a higher elevation than the entrance-negating this risk entirely. There is also very little chance of water entering the mine shaft through other means. Due to its mountain elevation, the risk of flood from rising ocean levels is also very unlikely. Additionally, piqlFilm is wrapped in waterproof, foil packaging as an extra level of protection against natural elements (including changes in humidity, light, etc).

\section{Bibliography}

Brudeli B.H., K.-M. Drake, A Holistic Approach to Digital Preservation, Piql preservation solution - outcome from Norwegian and European research projects (Archivator, MiLos, AsToR). Piql AS Paper.

Cross-Interleaved Reed-Solomon Coding(CIRC), Wikipedia The FreeEncyclopedia, https://en.wikipedia. org/wiki/Cross-interleaved_Reed\%E2\%80\%93Solomon_coding. Accessed 29.11.2021.

Generic 4K Frame Format. 4K Frame Structure description, Piql AS, rev. 170630.

Generic Preservation Reel Structure Specification, Piql AS, rev. 170125. 
GitHub, Archival File System, https://github.com/piql/afs. Accessed 26.10.2021.

GitHub, Boxing, https://github.com/piql/boxing. Accessed 26.10.2021.

ISO 18901:2010 Imaging materials - Processed silver-gelatin-type black-and-white films - Specifications for stability.

ISO 18924:2013 Imaging materials - Test method for Arrhenius-type predictions.

ISO 18936:2012 Imaging materials - Processed colour photographs - Methods for measuring thermal stability.

piql AS, Piql Technology - behind the scenes, https://www.piql.com/whitepapers/other-paper/ piql-technology-behind-the-scenes. Accessed 29.11. 2021.

piqlFilm - Transportation \& Storage Instructions based on ISO 18911:2010 (E) and ANSI ${ }^{\circledR}$ IT9.111991, Piql AS, rev.190902.

piqlFilm product specification, Piql AS, rev. 180121.

piqlReader. Technical specifications, Piql AS, rev. 200205.

Processing KODAK Motion Picture Films, Module 15. Processing Black-and-White Films, 2000, https://www.kodak.com/content/products-brochures/Film/Processing-KODAK-MotionPicture-Films-Module-15.pdf. Accessed 29.11.2021.

Recommendation for Space Data System Practices. Reference model for an Open Archival Information System (OASIS). Recommended practice CCSDS. 650.0-m-2 Magenta Book. June 2012, http://public.ccsds.org/publications/archive/650x0m2.pdf. Accessed 29.11.2021.

“SMPTE Motion Imaging Journal”, 2003-09, vol. 112, No 9, DOI 10.5594/SMPTE.ST139.2003, https://archive.org/details/sim_smpte-motion-imaging-journal_2003-12_112_12. Accessed 26.10.2021.

Test Rapport (TR) for Longevity of the Photographic film P1 from Kodak, Norner Project No 2222160, Technical Report 26.10.2021.

Texas Instruments, http://www.ti.com. Accessed 29.11.2021. 